\title{
Consensus and a Unified Species Paradigm: Reality or Idle Hope?
}

\author{
Stijn Conix*
}

\begin{abstract}
Many systematic biologists claim that a new paradigm about species classification has been established in their discipline. This paradigm, which I call the 'unified species paradigm', consists in a set of theoretical claims and methodological practices centered around the view that species are independently evolving lineages. This paper sets out the basic theoretical and methodological principles of this new paradigm, and looks at biological textbooks, publication patterns and citation patterns to evaluate the claim that there is growing consensus about it.
\end{abstract}

\section{Keywords}

Evolutionary Species Concept $\bullet$ paradigm shift $\bullet$ species delimitation $\bullet$ species classification $\bullet$ taxonomy $\bullet$ textbook analysis $\bullet$ bibliometric analysis

\section{Introduction}

It has long been common for papers about the species concept to start by pointing out how much has been written about the species problem, how vexing a problem it is, and how unlikely it is that biologists will ever agree about the definition of species. This was confirmed by a recent survey among biologists by Pušić et al. (2017), which revealed great diversity in the preferred species concept of biologists. At the same time, many recent systematic studies suggest-often in passing - that biologists have reached agreement about what species are, namely, independently evolving lineages (Carstens et al. 2013). For example, Weisrock et al. (2010, 1) write that 'through decades of diverging opinions, at least one component of the species problem-the disagreement over what exactly species are-has found resolution in the consensus view that species are solely defined as separately evolving metapopulation lineages.' Similarly, Leliaert et al. $(2009,122)$ write that 'important conceptual progress has been made in thinking about species concepts' and that 'a vast majority of evolutionary biologists now accepts that species are

\footnotetext{
${ }^{*}$ Centre for Logic and Philosophy of Science, Institute of Philosophy, KU Leuven, Vesaliusstraat 2, 3000 Leuven, Belgium, stijn.conix@kuleuven.be (iD) https://orcid.org/0000-0002-1487-0213
}

Received 10 May 2020; Revised 28 December 2020; Accepted 28 December 2020 doi:10.3998/ptpbio.2102 
lineages'. This view is so widespread that in a recent review of the field Padial and De La Riva (2020; see also Leliaert and Clerck 2017; Fišer, Robinson, and Malard 2018) even speak of a 'paradigm shift' in our view of species.

This paper will not evaluate whether this new paradigm is consistent, useful and an effective solution to the species problem. Similarly, I do not commit to a particular view on scientific concepts and the extent to which they are determined by pragmatic concerns or by what the world is like. Rather, the objective of this paper is purely descriptive: I aim to investigate whether, contrary to claims about the irresolvable nature of disagreements about species concepts, the paradigm of species as independently evolving lineages has indeed gained broad acceptance among taxonomists and other systematic biologists. To do this, Section 2 summarizes the main components of the paradigm associated with the view that species are independently evolving lineages. Sections 3, 4 and 5 then investigate biological textbooks, recent publications on species concepts, and the citations of these publications to investigate the extent to which claims about the resolution of the species problem by this paradigm reflect the opinion of most systematic biologists. Section 6, finally, concludes the paper and lists some limitations of this study.

\section{The Unified Species Paradigm}

Because of its continued use of the Linnaean system, taxonomy is one of the few fields of research that is still recognizably similar to what it was 300 years ago. However, behind the seemingly stable cover of Linnaean ranks, taxonomy has gone through fundamental and radical changes over the past centuries. I will not discuss or evaluate the various historical accounts of this change, which differ in the pivotal thinkers they emphasize and the revolutions they identify (e.g., Mishler 2009; Zachos 2016; Wilkins 2018). Rather, I will investigate where taxonomy stands now, and how it has changed over the past two decades. More precisely, I will investigate whether there is indeed growing consensus about the view that species are independently evolving lineages. For convenience of expression, I will refer to this view, and the set of other theoretical claims and methodological practices associated with it, as 'the unified species paradigm'.

The theoretical basis of the unified species paradigm has long been implicitly assumed by many biologists. It has been expressed explicitly and famously by de Queiroz $(1998,2007)$ and Mayden (1997) among others. It can be summarized by three closely related points:

- The Evolutionary Species Concept: Biological species are defined as independently evolving lineages. This is the conception of species described by Simpson (1951), Wiley (1978) and Mayden (1997) as the Evolutionary Species Concept (ESC), and, more recently and very popularly, by de Queiroz $(1998 ; 2007)$ as the General Lineage Concept or Unified Species Concept. 1 According to this view, species are ancestor-descendant populationlevel lineages that are on a unique evolutionary trajectory and evolve independently from other such lineages. In this paper, I will refer to this concept as the ESC.

- Conception vs. Delimitation: The ESC conception of species is distinguished from the practical delimitation of species. Because evolutionary independence is realized in many different ways in different groups, and because practical constraints on research also vary between taxa, delimiting species requires the use of a wide range of different methods and criteria. In some groups, evolutionary independence is signaled by differences in

\footnotetext{
${ }^{1}$ de Queiroz (1998) does not consider his two species concepts fully identical to the ESC. However, for the purposes of this paper, the differences between them are not relevant.
} 
mating calls or other barriers to reproduction, while in other groups morphological criteria, genotypic clusters, or reciprocal monophyly provide a more appropriate gauge. One major consequence of this is that the unified species paradigm considers traditional species concepts such as the Biological Species Concept (BSC) or the various forms of the Phylogenetic Species Concept (PSC) particular operationalizations of the more general ESC.

- Species as fallible bypotheses: It follows from the first two points that species delimitation consists in raising hypotheses about the existence and independent evolution of population-level lineages. These hypotheses can and should be tested by a wide range of methods that target different aspects of evolutionary independence. Together, such different tests allow taxonomists to understand the unique and often complex way in which different lineages are (or are not) evolving independently. Thus, while a positive signal from multiple such tests often makes a species-hypothesis better supported, it is also possible that a lineage is evolving independently even if only one of many available methods suggests that this is the case (Padial and De La Riva 2010).

These three principles are closely related: Because the theoretical conception of species is very abstract (first principle), it can encompass the various traditional species concepts as different but compatible methods of species delimitation (second principle); and it is because species delimitation has been severed from the species concept (second principle), that we can think of species as hypotheses to be tested by a wide range of methods (third principle).

Various authors (Mallet 2001, 8; Ereshefsky 2011, 74-75) have pointed out that this theoretical framework does not solve the species problem, as the ESC is so abstract and broad that the problem of defining species is simply moved to the choice of operationalizations in taxonomic practice. In light of this criticism, it is perhaps better to say that this framework resolves rather than solves the species problem: the distinction between the concept of species and species delimitation severs the practice of identifying species from theoretical debates about what species are. As long as taxonomists agree that species are independently evolving lineages, this framework allows them to focus on the practice of testing the independence of lineages. And indeed, the past two decades have witnessed a true renaissance in work on methods of species delimitation, often connected explicitly to the ESC and de Queiroz's exposition of it (e.g., Sites and Marshall 2003; Camargo and Sites 2013).

Thus, methods of species delimitation are a core component of this paradigm of species: the species problem ought not to be solved through conceptual advancements or further philosophical debate, but by improving our methods for identifying concrete lineages and by collecting more data. In accordance with the second and third principles, these methods are diverse and span a wide range of biological disciplines. However, four more general trends are worth emphasizing:

- Lineage-level and population-level processes: Because species delimitation consists in identifying independently evolving lineages, one major aim of methods of species delimitation is distinguishing patterns caused by population-level processes from patterns caused by lineage-level processes. While both population-level and lineage-level processes can cause various kinds of similarity between organisms, only the latter indicate independent evolution. By focusing on the relation between these two, the unified species paradigm

\footnotetext{
${ }^{2}$ The view that species delimitation consists in testing hypotheses about the independence of lineages should not be confused with Kirk Fitzhugh's (2009) view of species as explanatory hypotheses.
} 
has led to methods that bring together population genetics and phylogenetics. Most popular here are methods employing the multispecies coalescent model to estimate species trees while taking into account population-level processes that cause discordance between species trees and gene-trees (Degnan and Rosenberg 2009; Fujita et al. 2012). 3

- Contrast with 'traditional taxonomy': Traditionally, species delimitation relied heavily on the use of morphological traits. This way, cryptic diversity in morphologically similar groups often remained unnoticed. Hence, even though morphological evidence can be useful for identifying independently evolving lineages too, species delimitation under the unified species paradigm rarely relies solely on morphology and often has the explicit aim of checking for independently evolving lineages that are not morphologically distinct (Lumbsch and Leavitt 2011; Carstens et al. 2013).

- Integrative taxonomy: Proponents of the unified species paradigm often urge to use multiple lines of evidence for species delimitation, and integrate these in a comprehensive view on the investigated groups. This is important because there is no single operational criterion that always indicates evolutionary independence and that all independently evolving lineages consistently instantiate. By combining different methods, an integrative taxonomy' minimizes the chance of mistakenly recognizing or rejecting a species because the single line of evidence used was not appropriate for that group (Padial et al. 2010; Schlick-Steiner et al. 2010).

- Methodological sophistication: Over the past two decades, biologists have revealed enormous complexity in the evolutionary processes that shape groups of organisms. The ubiquity of lateral gene transfer (in prokaryotes) and introgression (in eukaryotes) means that genes can be exchanged between different lineages, and the ubiquity of incomplete lineage sorting means that it is probably never the case that all gene-trees of a population reflect the correct history of speciation. In response to this complexity, a wide range of new, often model-based methods of species delimitation has been developed over the past two decades. These methods are increasingly sophisticated and able to take into account increasingly more variables and confounding factors (Sites and Marshall 2003; Camargo and Sites 2013).

Note that I do not claim that these four trends are due to a theoretical paradigm shift. They are clearly also driven by technological progress and new techniques, models and kinds of data that have become available. Moreover, it is theoretically possible to do research that fits in these trends without subscribing to the unified species paradigm. However, there is a clear and tight fit between the unified species paradigm and these methodological trends, and those who support the former are typically actively engaged in the latter. Rather than causing the unified species paradigm, then, it is most accurate to say that these methodological practices are a part of it.

These three theoretical principles and four methodological trends capture the main tenets of the unified species paradigm. In the remainder of this paper, I look at recent biology textbooks, recent publications, and citations to investigate whether claims about broad and increasing acceptance of this paradigm are justified.

\footnotetext{
${ }^{3}$ It is debatable, however, whether these methods are always successful at distinguishing population-level processes and lineage-level processes. Notably, Sukumaran and Knowles (2017) show that methods of species delimitation using the multispecies coalescent track genetic structure, which does not always reflect species boundaries.
} 


\section{Textbooks and Species Concepts}

Thomas Kuhn (1962) famously emphasized the role textbooks play in consolidating and perpetuating scientific paradigms. Textbooks summarize the ruling paradigm as well as the main problems, aims and values that shape what Kuhn calls 'normal science' in that paradigm. As new generations of scientists learn their trade through these textbooks, they ensure that these scientists work within this paradigm. Whenever a scientific revolution occurs, according to Kuhn, textbooks have to be rewritten so as to reconstruct scientific history in a way that represents it as linear progression towards the ruling paradigm.

Regardless of whether Kuhn's view on scientific change is accurate, it is plausible that scientific textbooks typically contain brief summaries of the paradigm that is in place around the time of publication. It is also plausible that they have substantial influence on the paradigms that biologists come to accept and work in. Hence, surveying textbooks is one way of testing the claim that the unified species paradigm in taxonomy is firmly established, and surveying change in textbooks over time is one way of tracking changes in this paradigm over the past decades.

\subsection{Methods}

I collected various editions of authoritative, widely used and long-running textbooks in biology and evolutionary biology. For convenience, I refer to these textbooks by one of their authors. Table 1 provides an overview of these textbooks and the editions that were surveyed, and more information on each edition as well as a list of the consulted chapters is included in the Appendix (A1). I had nearly complete coverage of Campbell's Biology and Solomon's Biology from the 1990s until now. The editions that I consulted of Futuyma's textbooks on evolutionary biology provide similarly consistent coverage, but were published with more time in between two editions and include two distinct but similar series of books (Evolutionary Biology until 1998 and Evolution after that). The coverage of the other textbooks was more patchy. I also checked textbooks in ecology (Townsend, Begon, and Harper 2008; Krebs 2009; Smith and Smith 2015) and conservation biology (Hunter and Gibbs 2009). As these generally contained no discussion of species concepts, classification or systematics, they were not included in this study.

For each available edition of each textbook, I read all chapters or sections devoted to the species concept, classification or systematics more generally. For each edition, I checked the number of species concepts that are discussed, whether the ESC is mentioned as the overarching concept, and whether an emerging consensus about the species concept in taxonomy is men-

Table 1: Overview of the textbooks surveyed for this study.

\begin{tabular}{lllr}
\hline Textbook & Time period & Editions included & $\mathbf{n}$ \\
\hline \multicolumn{3}{l}{ General Biology } \\
\hline Campbell & $1990-2020$ & $2-11$ & 10 \\
Solomon & $1985-2019$ & $1,3-11$ & 10 \\
Raven & $1999-2017$ & $5-9,11$ & 6 \\
Kimball & $1974-1982$ & $3-5$ & 3 \\
\hline Evolutionary Biology & & \\
\hline Futuyma & $1986-2017$ & 2,$3 ; 1,3,4$ & 5 \\
Freeman & $2001-2014$ & 2,5 & 2 \\
Ridley & $1993-2004$ & 1,3 & 2 \\
\hline
\end{tabular}

๑ OPEN ACCESS - PTPBIO.ORG 


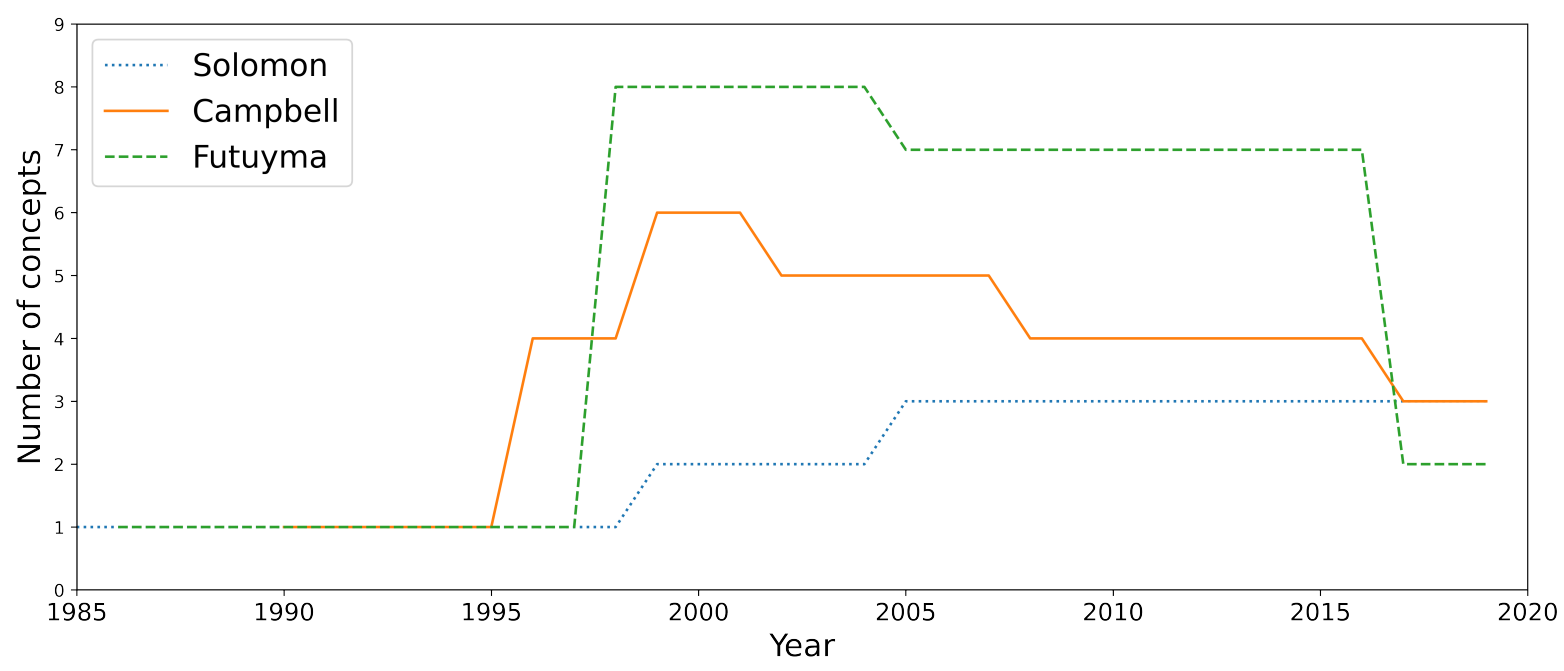

Figure 1: Number of species concepts discussed in the three textbooks with good coverage.

tioned. Because the unified species paradigm involves a shift from theoretical to practical issues, I also tracked how much space in the chapters on systematics was devoted to classification and theoretical taxonomic debates as compared to practical, methodological and operational discussions.

\subsection{Results}

In the three textbooks for which there was coverage of the full period (Campbell, Solomon, Futuyma), there was a clear increase in the discussed number of species concepts until the early 2000s. The three textbooks initially only discuss the BSC, and then gradually add additional concepts from the mid-1990s. The number of species concepts discussed in Futuyma and Campbell then decreased strongly (from 8 and 6 to 2 and 3 respectively) over the past decade (see figure 1), but remained constant in Solomon (3). One explanation for this difference is that the chapter on species concepts in Solomon has not changed since 2005, while in Campbell and Futuyma was updated multiple times.

Of the remaining textbooks, Raven's shows a similar pattern with 2 concepts up to 2005 and after 2017, and 3 in between. As only two editions of Ridley's (7 and 3 concepts) and Herron's (3 concepts) were available, no trend could be derived from those textbooks. In the final editions that I surveyed, all textbooks mention the BSC. Other species concepts still commonly discussed are the PSC, the Morphological Species Concept and the Ecological Species Concept.

All the general textbooks (Solomon, Campbell, Raven) emphasize that there are many species concepts, and that there probably is no single concept that is always correct. In line with this, none of these textbooks claims that there is an emerging consensus that species are independently evolving lineages. If the ESC is discussed (Campbell, 5; Raven, 6; Solomon, 7-11), it is as one among many possible species concepts. In contrast with this, two of the textbooks on evolutionary biology do mention consensus concerning the ESC. Futuyma's 2013 (460) cites de Queiroz 2007 and claims that 'all definitions of species share the notion that species are independently evolving lineages', and that they differ 'as to the properties that define those lineages'. However, this passage is removed again in the dramatically shortened discussion of species concepts in the next edition. In both surveyed editions of Freeman, the authors explicitly state that biologists agree that species are independently evolving lineages, and that different traditional species concepts provide different operational criteria for species delimitation. 
In all textbooks with long-term coverage, the space devoted to taxonomy, classification, and theoretical discussion of classification decreases over time. This is most obvious in the way that so-called schools of taxonomy are discussed. The early editions of all textbooks contain a substantial discussion of classical evolutionary taxonomy, phenetics, and cladistics, often with an explicit preference for classical evolutionary taxonomy and explained by means of the example of the legitimacy of Aves and Reptilia as valid taxa. Over time, these discussions then get shortened and limited to cladistics. In Campbell, the discussion of schools of taxonomy disappears in the 1999 edition, in Raven and Futuyma in 2005, and in Solomon this is moved to a historical section in 2015. Parallel to this, discussion of topics such as naming, ranks, taxonomic criteria, the Phylocode, classification and lumping/splitting were gradually shortened or completely removed in all these textbooks over the past two decades. Over the same period, all long-running textbooks gradually expanded their discussion of phylogenetics, with increasingly more attention for cladistics and various molecular methods used for it.

These trends of decreasing coverage of taxonomy/classification and increasing coverage of phylogenetics and methodological issues can be illustrated by comparing the early and late editions of the textbooks. For example, the second edition of Campbell's Biology (published in 1990) contained about 5 pages on taxonomy and classification, and about 2 pages on other, methodological aspects of systematics. The chapter that deals with systematics in the eleventh edition of the same textbook (published in 2017), contains about 2 pages on classification and between 10 and 15 on other aspects of systematics. ${ }^{4}$ Similarly, the chapter on systematics in the third edition of Solomon's Biology (1993) is titled 'the classification of organisms', and contains about 9 pages on classification and about 2 on other aspects of systematics. In the eleventh edition (2019), this title has changed to 'Systematics: Understanding diversity', and classification and other aspects of systematics get respectively 6 and 11 pages. Finally, the sixth edition (1999) of Raven's Biology has 6 pages on classification, and no focused discussion of phylogenetics or cladistics. The eleventh edition (2017) has 4 pages on classification-mostly devoted to species concepts-and 13 pages on other aspects of systematics.

\subsection{Discussion}

The textbooks analyzed here do not reflect an emerging consensus on the ESC. Instead, they all devote most attention to the BSC and often even explicitly endorse a pluralist position concerning species concepts. Thus, claims about the unified species paradigm are not confirmed in this way. However, while general textbooks do not mention the consensus concerning species as evolutionary lineages, textbooks on evolutionary biology do. This suggests that it might be that textbooks on evolutionary biology are a better gauge of trends in systematics, and that it takes more time for changes in systematics to be taken up in general textbooks. This explanation is supported by the fact that Solomon and Campbell still explicitly endorsed classical evolutionary taxonomy when it had already been largely abandoned (in 1996 and 2002 respectively), while neither of the earliest consulted editions of textbooks in evolutionary biology (Futuyma in 1986 and Ridley in 1993) endorse this approach to classification.

Other trends in the textbooks are more in line with the claims about the unified species paradigm. First, the number of species concepts discussed in various textbooks was at a peak in the early 2000s, and steadily decreased after that. Together with shortening sections on taxonomy and the preferred theoretical framework for it, this suggests that interest in theoretical

\footnotetext{
${ }^{4}$ These comparisons of pages dedicated to classification and pages dedicated to parts of systematics not involved in classification are inevitably approximations, as often sections deal with a mixture of both. However, the differences between early and late editions are large enough for the result to be clear despite this difficulty.
} 
questions concerning species classification decreased. At the same time, discussion of cladistics and phylogenetic methods strongly increased, suggesting that interest in methods of systematics increased. Both trends are in line with the way the unified species paradigm resolves the species problem by focusing on methodological matters. However, it should be noted here that the time-span of these textbooks coincides with the introduction and popularization of molecular data in systematics and evolutionary biology. This led to the development of a wide range of new methods and revolutionized these fields in a way that would be taken up in textbooks regardless of conceptual changes or changing evaluation of the relative importance of theoretical and practical issues. Hence, the extent to which the increasing attention devoted to phylogenetic methods reflects a paradigm change in taxonomy is unclear.

\section{Documents and citations on species concepts}

While textbooks provide insight into paradigms that have been fully accepted for a substantial time, they may not be up to date with more recent changes in a field. Particularly when the textbooks are not devoted solely to the field in question - as was the case here-they are unlikely to be the best tool to track recent changes. Scientific publications are in that sense complementary to textbooks, as they appear more regularly and typically deal with the state of the art of the field. Such publications are also useful to test how broadly certain ideas are used in a field, namely, through citation counts. This does not work for textbooks, as their influence often extends beyond their cited use. This section looks at both publications and citations for further tests of the paradigm-change in taxonomy.

At least two testable predictions can be derived from the claim that consensus concerning the unified species paradigm is gradually emerging. If there is growing agreement to define species as independently evolving lineages instead of using other traditional species concepts, it should be expected that documents describing the ESC tend to get cited more often over time, and documents describing the traditional species concepts tend to get cited less often over time (call this prediction 1). Because the unified species paradigm focuses on operationalization rather than the species concept, one would also expect that the number of documents dealing with conceptual issues tends to decrease while the number of documents dealing with methods of species delimitation should increase (call this prediction 2).

\subsection{Methods}

To test prediction 1, I compiled a list of the main publications connected to the various species concepts. For the ESC, I selected the two most cited papers by de Queiroz (namely, his 1998 and 2007) on his solution to the species problem as well as Mayden's (1997) influential paper on the same topic. Even though they were not the first to discuss the ESC (see Simpson 1951; Wiley 1978), their names and work have become closely associated with the unified species paradigm. For the other species concepts, I relied on the comprehensive list of Zachos (2016, chapter 4) and selected the main references that were given for each of the 32 species concepts discussed there, as well as the main references for two new species concepts discussed in Zachos (2018). Of these 34 concepts, the Nothospecies Concept, Taxonomic Concept, Morphological Concept, Phenetic Concept, Successional Concept, and Agamospecies Concept could not be included as their main references (or citations of these references) were not indexed in the online version of Clarivate Analytic's Web of Science (WoS). [1 In addition, the notions of Evolutionary

\footnotetext{
${ }^{5}$ www.webofknowledge.com
} 
Significant Unit, Least Inclusive Taxonomic Unit and Non-dimensional Species were not included because they are not strictly speaking species concepts. The Reproductive Competition Concept was considered a version of the BSC and therefore not included separately. Finally, the ESC and de Queiroz's Unified Species Concept and General Lineage Concept were considered the same and not included in the list of non-ESC concepts. For each of the remaining concepts I selected multiple references (BSC, diagnosability PSC, monophyly PSC) or the most prominent reference (all other concepts).

I then pooled the ESC documents in one group, and the other documents in another group, and retrieved citation numbers per year for both groups from WoS. Because this test aims to track the change over time in the proportion of systematic biologists that uses these documents (rather than change in absolute numbers of use), citation numbers for each year were made relative to the total number of relevant documents published that year. More precisely, citation numbers for each year where divided by the total number of documents for that year in the $15 \mathrm{WoS}$ categories that cite documents about species most often. This way, the results do not merely reflect the increasing coverage of WoS or general increase in scientific publications. Note that because the two groups of documents differ in size and consist of records published at widely different times, these relativized citation numbers cannot be used to compare the influence of these groups. Rather, they show how interest for each of these groups changed over time, and allow us to compare these trends. To do this, a Spearman correlation between year (1998-2019) and relativized citation number was calculated using the cor.test () function from the stats package in R. The correlation estimates $(\rho)$ were tested using a two-sided test from the same function.

To test prediction 2, I searched WoS in all databases for documents published between 1990 and 2019 with 'species delimitation' in their title, and for documents with either 'species concept' or 'species definition' in their title. In addition, I searched for documents on at least one of 9 main species concepts (excluding the ESC). 9 Because almost no documents mention these in their title, I also included documents with one of these species concepts in their abstract or keywords. For each of the three search results, I also retrieved how often they were cited each year between 1990 and 2019. Again, the results were divided by the same number of relevant WoS documents for the year of publication or citation to control for the increase in WoS coverage and general publication and citation numbers over time. The Spearman correlation was then calculated between year and the relativized citation and publication numbers for 1998-2019. Note that, as there are more citable documents as we move closer to the current year (e.g., documents published in 1998 can still be cited in 2000, but documents published in 2000 could not yet be cited in 1998), the number of citations for each year can be expected to increase regardless of the popularity of these documents. Still, it is relevant to compare this measure between the three groups.

\subsection{Results}

The correlation estimates for prediction 1 are summarized in table 2, and show a strong correlation between year (1998-2019) and relativized citation numbers of the ESC group, and a strong negative correlation between year (1998-2019) and relativized citations numbers for all other concepts. A similarly strong negative correlation was found between year and the relativized cita-

\footnotetext{
${ }^{6}$ For the full list of concepts (and corresponding papers) included in the search, see Appendix (table A4.

${ }^{7}$ See Appendix (table A5) for the list of Web of Science categories included.

${ }^{8}$ https://www.r-project.org/

${ }^{9}$ See Appendix (A) for the precise search terms.
} 

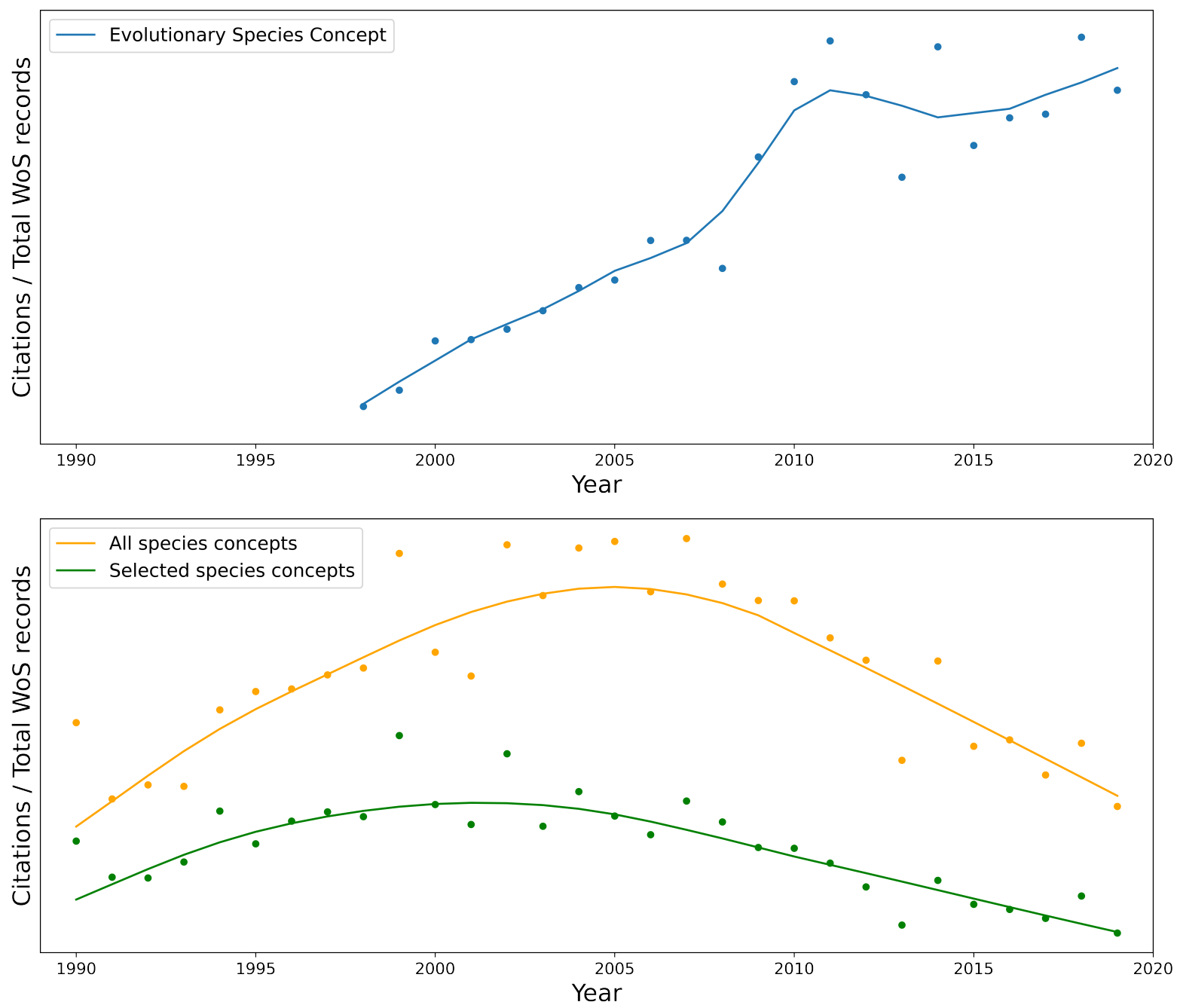

Figure 2: Number of citations of the ESC documents (top) and the documents about other species concepts (bottom) relative to the total number of relevant publications in WoS. The dots indicate the relative number for each year. The nonlinear trend line has been generated using a LOESS smoother in Microsoft Excel (PTS Loess add-in; $\alpha=0.33$ ).

tions of a selection of non-ESC concepts consisting of the BSC, the monophyletic PSC, the diagnosability PSC, the Recognition Species Concept, the Cohesion Species Concept, and the Genotypic Cluster Species Concept. ${ }^{10}$ Figure 2 visualizes the changes in citations of the ESC (top, 1998-2019) and other concepts (bottom, 1990-2019) over time. Citations of the ESC documents have increased more or less steadily since their publication, and ESC documents have never been cited more often than over the past two years. In contrast with this, citations of all other species concepts and selected other concepts increased up to the early 2000s, and decreased after that.

The correlation estimates for prediction 2 are summarized in table 3 . There was a strong positive correlation between year and documents with 'species delimitation' in their title, but no significant correlation between year and documents with 'species concept' in their title or one of the various species concepts in abstract or keywords. Figure 3 (top) visualizes this, and shows

\footnotetext{
${ }^{10}$ The results for these 6 species concepts, based on only 1 rather than multiple papers, are included here because they figure in the citation context analysis discussed in the next section. For the list of papers of these 6 concepts, see Appendix (table A3.
} 
Table 2: Spearman's rank correlation coefficient for the change over time of relativized ESC-citations, citations of all other concepts, and citations of the 6 selected concepts.

\begin{tabular}{lrl}
\hline Trend & Spearman's $\rho$ & p-value \\
\hline ESC documents & 0.8949746 & $3.30152 \times 10^{-6}$ \\
All concepts documents & -0.8836815 & $2.72949 \times 10^{-6}$ \\
Selected concepts documents & -0.6250706 & 0.002329987 \\
\hline
\end{tabular}

that while the numbers of documents on species concepts (both in title and in abstract/keywords) has been stable since 1990, there was a strong increase in documents on species delimitation in the early 2000s. As expected (as more documents are added to the pool throughout the years), there was also a strong correlation between year and relativized citations for all three groups. However, as shown by figure 3 (bottom), this increase is much weaker for documents on 'species concept' and the various species concepts than for documents on species delimitation. To compare the number of documents with 'species concept' and 'species delimitation' in their title, figure 4 represents the proportion of these two groups in all documents with either in their title. This figure shows clearly that until 2005, documents on the species concept were far more common, whereas after that point documents on species delimitation became dominant.

Table 3: Spearman's rank correlation coefficient for the change in relativized documents and citations of 'Species delimitation', 'Species concept', and the various species concepts.

\begin{tabular}{lcc}
\hline Measure & Spearman's $\rho$ & p-value \\
\hline Species delimitation documents & 0.945 & $4.03 \times 10^{-6}$ \\
Species concept documents & -0.333 & $1.31 \times 10^{-1}$ \\
Various species concepts documents & -0.34 & $1.21 \times 10^{-1}$ \\
Species delimitation citations & 0.98 & $3.15 \times 10^{-6}$ \\
Species concept citations & 0.976 & $3.26 \times 10^{-6}$ \\
Various species concepts citations & 0.96 & $3.72 \times 10^{-6}$ \\
\hline
\end{tabular}

\subsection{Discussion}

Prediction 1-that citations of the ESC would increase while those of other species concepts would decrease over time-was confirmed by the test in this section. Citations of documents on other species concepts increased until around 2005, and decreased gradually after that. It was also around this time that citations of the ESC started increasing strongly. Interestingly, this matches the time of the peak of species concepts in the textbooks discussed in the previous section. This suggests that the debate about species concepts was influential and particularly active over the 1990s and with a peak in the early 2000s, after which its influence gradually decreased. Conversely, the ESC as a resolution to the species problem clearly won in importance over the past two decades, and seemingly continues to do so.

Prediction 2-that the number of documents on species delimitation would increase while those on species concepts would decrease over time-was also confirmed by the test in this section. The number of documents on the species concept and documents on particular species concepts remained rather stable over the past decades, while documents on species delimitation increased strongly from around 2005 on. This confirms the pattern of the absolute number of 

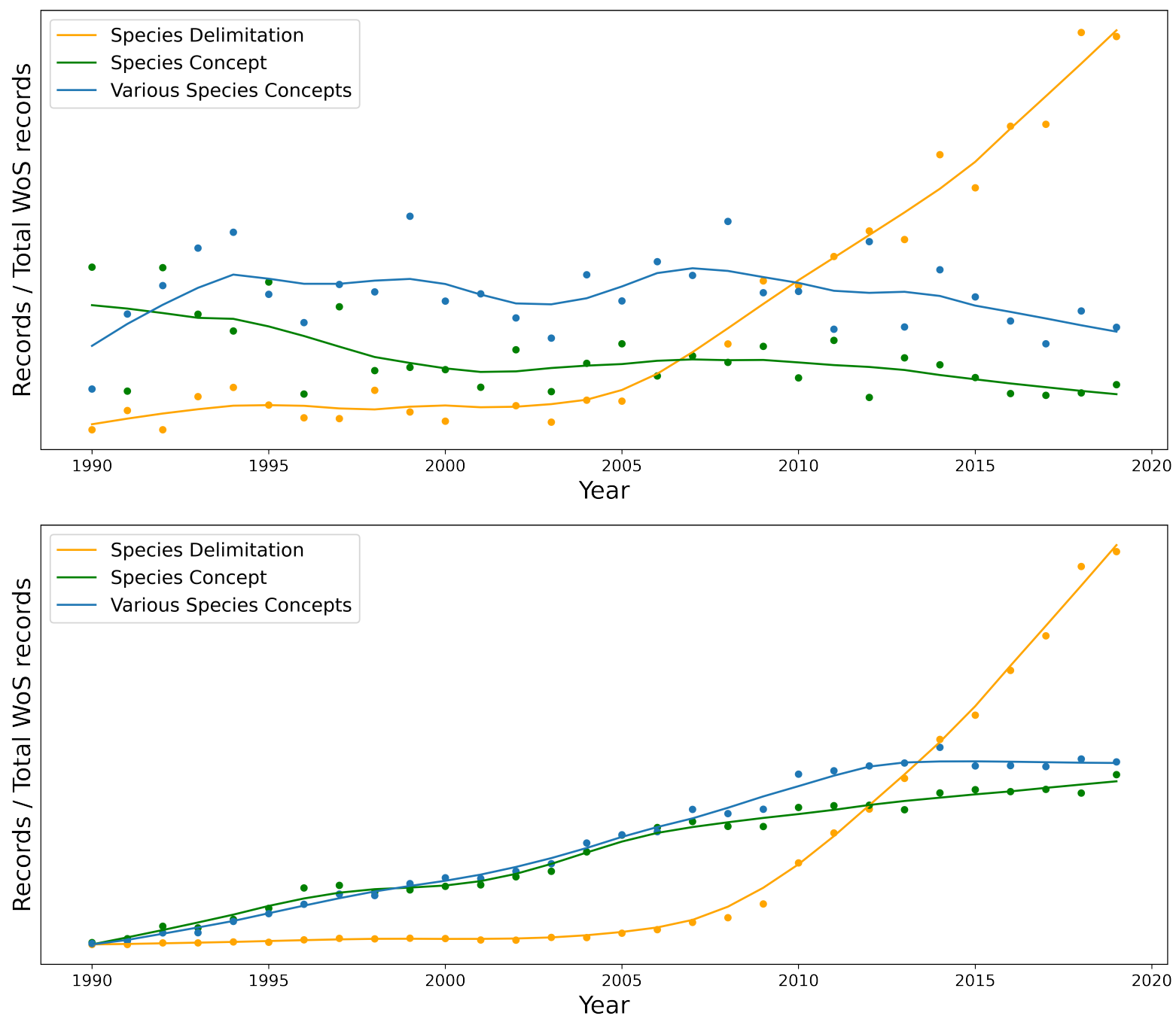

Figure 3: Number of documents (top) and citations (bottom) on 'species delimitation', 'species concept' and the various species concepts relative to the number of WoS documents. The dots indicate the relative number for each year. The nonlinear trend line has been generated using a LOESS smoother in Microsoft Excel (PTS Loess add-in; $\alpha=0.33$ ).

documents on species delimitation and related terms (cryptic species and species tree) reported in Camargo and Sites (2013). The decreasing influence of debates on species concepts as compared to species delimitation is also reflected in the citation numbers, which over the past decade increased far more strongly for documents on species delimitation than for documents on species concepts. While this is of course also the direct effect of the different rate at which the total number of documents on each of these topics increases, it shows clearly which of these topics currently attracts most attention.

\section{Citation context analysis}

The tests in the previous section use citation numbers to estimate how use and discussion of different species concepts has evolved over time. One important limitation of this is that citations are not always used to express support for or use of a particular concept. Indeed, concepts are also likely to be cited whenever they are criticized. Hence, high citation numbers need not always indicate that the concepts discussed in those documents are generally accepted. The study 


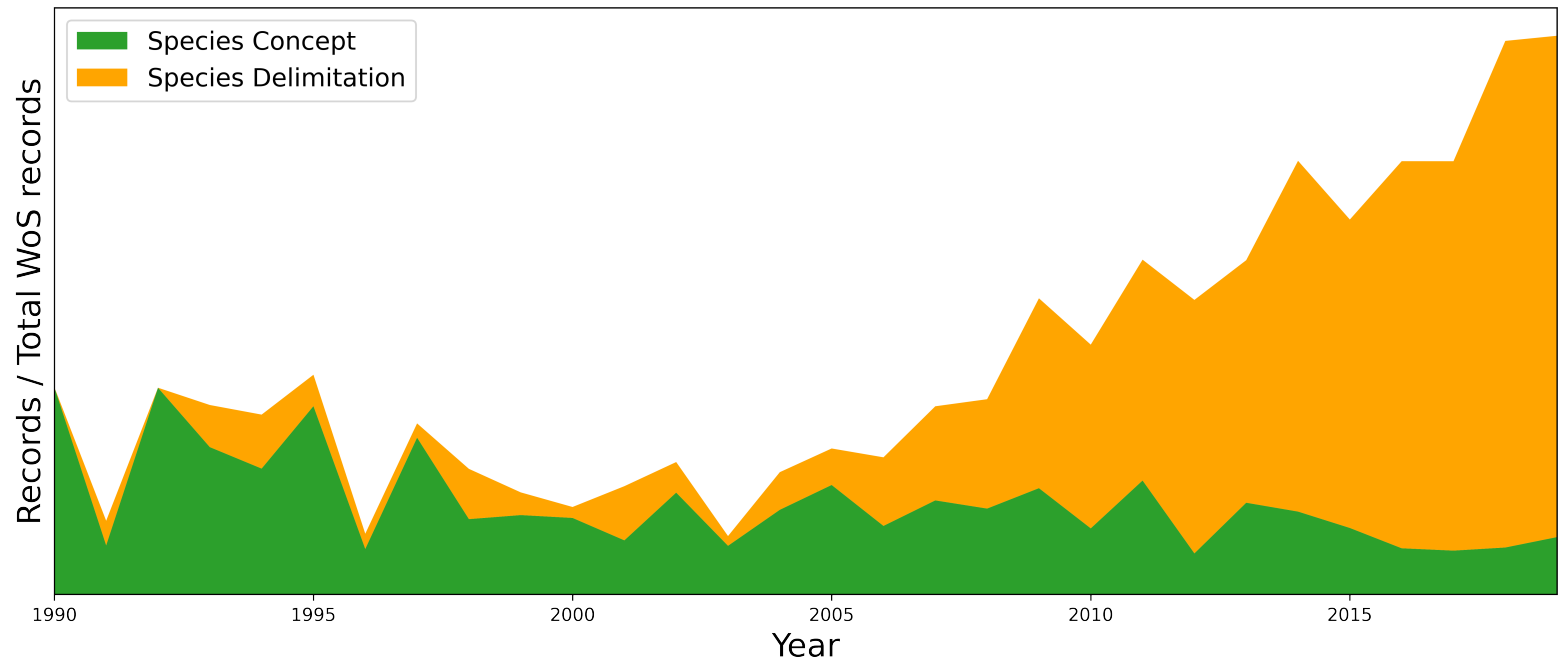

Figure 4: Proportion of documents with 'species delimitation' or 'species concept' in their title, relative to the total number of WoS documents.

of citations that looks at the context of the citation to determine the kind of link between documents it constitutes, is known as citation context analysis (Small 1982; Bornmann and Daniel 2008; Petrovich 2018). This section uses such citation context analysis to get a better understanding of the citation numbers used in the previous section. More particularly, it will look into citations of the ESC and of the traditional species concepts to distinguish between citations that indicate acceptance, support or use, and citations that do not indicate this and perhaps even indicate rejection or criticism. This way, it can be determined whether the different trends truly reflect an emerging consensus on the former, and a loss of interest in the latter. If claims about the unified species paradigm hold, it should be expected that over the past two decades documents on the ESC were more often cited to indicate use or support, while documents on the other species concepts were less often cited in this way.

\subsection{Methods}

Like in the previous section, two groups of documents were selected to represent the ESC on the one hand, and the traditional species concepts on the other. De Queiroz's 2007 and 1998 were used for the reasons already described in the previous section: they are, more than any other papers, associated with the unified species paradigm. Because citation numbers were too high to code all 30 documents on the traditional species concepts, a selection was made to include a diversity of influential species concepts with highly cited papers published at the same time or before the two de Queiroz papers. This way, the monophyletic PSC (Donoghue 1985), the diagnosability PSC (Cracraft 1983), the BSC (Mayr 1942), the Ecological Species Concept (Van Valen 1976), the Recognition Species Concept (Paterson 1985), the Cohesion Species Concept (Templeton 1989) and the Genotypic Cluster Species Concept (Mallet 1995) were included.

For both groups of documents, the program Publish or Perish was used to download citation details from Google Scholar (which are more complete than WoS citation numbers). 11 Because for both groups the total number of citations was in the order of several thousands-and thus, too much to code manually - a selection was made. For the two de Queiroz's papers, the 100

\footnotetext{
${ }^{11}$ https://harzing.com/resources/publish-or-perish
} 
Table 4: Coding scheme for citations of the ESC and of the traditional concepts.

\begin{tabular}{ll}
\hline Use or support & $\begin{array}{l}\text { Any document in which the concept is explicitly en- } \\
\text { dorsed or explicitly used as the correct or best species } \\
\text { concept. }\end{array}$ \\
Any document in which explicit arguments against the \\
concept are given.
\end{tabular}

most cited documents of each paper were included, as well as the 5 most cited documents for each year between 1998 and 2018. Citation numbers are a useful method of selection here because the test aims to gauge the influence of de Queiroz's papers on scientific research. By coding the most cited documents, the results of the test will reflect how the most influential documents use the ESC. The top 5 most cited documents of each year since 1998 were included to make sure that the sample also includes recent influential documents which, because of their publication date, had much less opportunity to be cited. Finally, any document citing both the 1998 and 2007 was included only once and replaced by the next most highly cited document. Documents authored by de Queiroz or documents that did not have the citation in text were also replaced. Using these criteria, 217 documents citing either de Queiroz's 1998 or 2007 were selected for coding.

As the group of papers on the traditional species concepts contained more different papers and papers published sometimes long before the study period, a slightly different method of selecting citing documents had to be used here. First, I selected only documents published between 1999 (the year of the earliest included document citing de Queiroz) and 2018. This makes sure that both groups cover the same time period and that the results of the study reflect the recent influence of the ESC and the traditional species concepts. Second, to ensure that citations of all 6 papers were equally represented, I selected the 35 most cited documents for each of the 6 included papers. By using this number, the sample could be expected to be the same size as the one selected for the ESC. Third, for the reasons discussed in the previous paragraph I included the 5 most cited documents for each year and the most cited document for each author for each year. Finally, documents authored by the cited author and documents that did not contain the citations in text were excluded and replaced. Using these criteria, 298 documents citing at least one of 6 selected species concepts were selected for coding.

As the main aim of this test is to uncover whether the ESC and other species concepts were cited to indicate support, the coding scheme focused on this criterion. Table 4 provides an overview of the categories of the coding scheme. Note that documents were only included in these categories if the citation was clearly included in the document with the purpose described by the category. For example, if a document cites de Queiroz's 1998 and 2007 to refer to the species problem in general and then uses de Queiroz's framework without explicitly saying that the framework will be used, this was not coded as 'use or support'. As one document can cite another in more than one way, some documents were placed in multiple categories.

In addition to coding citations, I tracked how often documents refer to a paradigm-change or substantial conceptual shift in taxonomy, and indicate that there is a consensus or emerging 


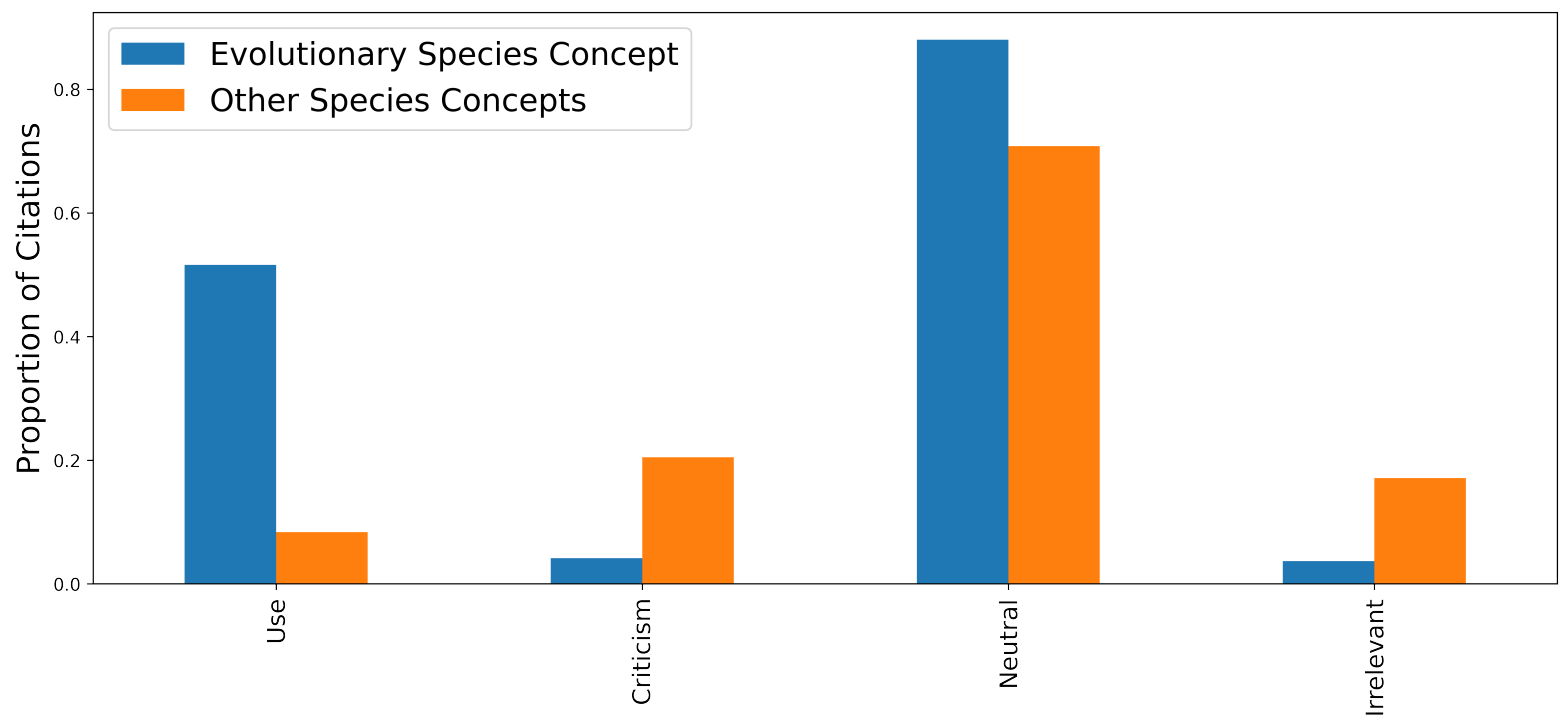

Figure 5: The proportion of documents citing the ESC and other concepts to indicate each of the four coding categories.

consensus about one of the concepts. This provides a way of testing the extent to which claims about the unified species paradigm are shared by biologists citing documents about species concepts.

\subsection{Results}

Figure 5 shows how often papers from the two groups were cited in the ways described by the four categories of the coding scheme. While both groups of papers are often cited in a neutral sense, there are large differences in the categories of 'use' and 'criticism': while just more than half of the documents citing the ESC did this to indicate their use of or support for his concept, less than $10 \%$ of the documents citing other concepts did this for that reason; conversely, those papers were cited substantially more often to criticize the species concepts discussed in them. For both 'use' and 'criticism', a Fisher's Exact Test shows that the difference between the ESC papers and the other papers is highly significant..12

In total, 30 documents (14\%) citing the de Queiroz's papers explicitly indicated that there is (emerging) consensus among biologists about this concept and/or that this concept constitutes a major conceptual shift in taxonomy. In addition, 41 documents (19\%) indicated that the ESC unifies the traditional species concepts. In comparison, only three documents indicate a near consensus about one of the other species concepts.

\subsection{Discussion}

The classification of citation types in this section confirms the predictions about an emerging consensus concerning the unified species paradigm. De Queiroz's papers were cited more frequently to indicate use, while papers about the other species concepts where cited more often to criticize them. This is compatible with the claim that there is a growing consensus about the ESC as the best conceptual framework to use in scientific research on species. Moreover, the low number of criticism-citations (compared to the other species concepts) suggests that influential documents rarely criticize this conceptual framework. All this means that the results

\footnotetext{
${ }^{12}$ For 'use', $\mathrm{p}<0.00001$ (odds ratio: 11.65 ); for 'criticism', $\mathrm{p}<0.00001$ (odds ratio: 0.17 )
} 
from the tests in the previous section can safely be interpreted as supporting prediction 1 tested there: increasing citations of the ESC indicate growing support for this concept. Indeed, the results from the test in this section suggest that a stronger interpretation is even justified. It is likely that more of the citations of other species concepts are for criticizing these concepts, and that more of the citations of the ESC are for supporting or using this concept. Hence, the gap between support for the ESC and for the other concepts is likely to be even bigger than suggested by the difference in the trends of the citation numbers of both groups.

The community-support for the unified species paradigm suggested by these tests is also reflected in the way many of the authors of these documents evaluate the conceptual position of the community: $14 \%$ of the documents citing the ESC explicitly state that there is growing consensus about this view among biologists.

The seemingly growing consensus about the ESC is in contradiction with the findings of Pušić et al.'s (2017) survey about the species concept in biology. They asked 193 biologists which species concept they prefer, and only 14 of those indicated preferring the ESC. About one third of all respondents stated they use the BSC, which was by far the most popular option. One plausible explanation for the divergence between the results of that survey and the tests in this paper is that none of the respondents identified as systematists or taxonomists. The most common disciplines in the survey population were ecology and molecular biology. Hence, these biologists are unlikely to closely follow conceptual changes in taxonomy or be aware of the most popular views in that field. Indeed, the popularity of the BSC among participants suggests that non-systematists might suffer from the same delay on conceptual change that could also explain the gap between biology textbooks and the systematic literature. The textbooks' influence on biologists might also be a partial explanation for the popularity of the BSC among non-systematists, as many of them might have had little contact with debates about species concepts since their education.

\section{Conclusions}

The tests in this paper largely confirm the claims about a growing consensus among taxonomists about the unified species paradigm as the most appropriate conceptual framework for thinking about species. If indeed widely accepted, this paradigm would resolve the species problem by shifting attention from theoretical questions to operational ones.

The evidence from textbooks forms one exception to this this conclusion, as for the largest part these textbooks did not endorse or even discuss this paradigm. However, these textbooks did bring to light another trend that was confirmed in subsequent tests, namely, that the theoretical debate on species concepts became increasingly influential throughout the 1990s, reached its most influential point in early in the twenty-first century, and then gradually decreased in influence. This is in line with the unified species paradigm's resolution of the species concept by focusing on operational rather than conceptual issues. In line with this, publication and citation numbers on species delimitation increased strongly over the past two decades, while the papers on the species concept clearly score worse on both parameters. One exception to this are papers on the ESC, which have been cited frequently over the past two decades by papers that use or support it.

To end this paper, I wish to make three remarks. First, it is interesting to note that the operational focus of the unified species paradigm fits nicely with Kuhn's (1962) view on scientific revolutions. Kuhn argues that a scientific field in crisis tends to focus on fundamental theoretical questions. Once a new paradigm arises from this period of crisis, Kuhn argues, the focus shifts from fundamental theoretical questions to solving practical puzzles that are suggested by

๑ OPEN ACCESS - PTPBIO.ORG 
whichever theoretical framework came out triumphant. Relevant is that the theoretical issues that dominated science during the period of crisis need not be solved but typically just shift out of focus. This is because scientists engaged in 'normal science' typically do not question the fundamental theoretical framework of the paradigm. Rather, they focus on solving the more fine-grained puzzles that emerge within the theoretical framework of the paradigm (see also Lakatos 1976).

This Kuhnian picture mirrors the ESC's resolution of the species problem, which consists in a broad, abstract definition of species as evolutionary lineages and a strong focus on developing sophisticated methods for identifying such lineages. Thus, rather than working out in detail what 'evolutionary independence' means, systematic biologists now focus on developing methods that can reconstruct species trees despite complexities like extensive introgression and incomplete lineage sorting. The focus thus lies on difficult operational problems rather than fundamental theoretical issues, and the latter are mostly dismissed as irrelevant to biological practice.

This parallel with Kuhn's crisis science and normal science should not be taken to mean that change in taxonomy over the past three centuries perfectly fits the Kuhnian view: the field has gone through many minor and major changes, with competing paradigms often operating side by side, and with both theoretical and practical problems continuously present in taxonomic debates (Mishler 2009; Wilkins 2018). In addition, some of the theoretical principles associated to the unified species paradigm may have been implicitly assumed or used by many taxonomists for a long time before they were spelled out in print. However, mapping paradigm change in taxonomy to Kuhn's view and investigating the implications for this view are subjects for a different paper.

A second point I want to draw attention to is that there are at least three important limitations to the conclusions we can draw from the tests in this paper. First, this paper only surveyed a small number of papers from taxonomy, and systematics more generally. More precisely, the papers that were taken into account here were mostly papers that are highly cited. This means that the results only reflect the conceptual views of a small part of the systematic community, and that they are biased towards the well-cited areas of systematics and taxonomy. This is significant because there are many small journals, often dedicated to particular taxa, that rarely accumulate citation numbers such as the ones of the papers used for this investigation. Moreover, amateurs form a substantial proportion of the taxonomic workforce (Fontaine et al. 2012). These amateurs typically do not have access to the same genomic or genetic methods as professionals. Hence, it is plausible that the views of amateurs on species concepts and methods of species delimitation are substantially different from the views reflected in the documents sampled for this investigation.

While an exhaustive investigation of the ruling paradigm in taxonomy should thus also test the views that are prevalent in areas of taxonomy that are cited less frequently, I do not think that this invalidates the results of this study completely. After all, it is likely that highly-cited papers and professional taxonomists have a stronger influence on what is-and will be-the ruling taxonomic paradigm: citation scores and influential publications weigh heavily in the distribution of research funds, and professional taxonomists are typically also responsible for educating new generations of taxonomists. Hence, even if there is a divide currently, it is likely that the view of highly cited, professional taxonomists becomes more influential over time.

A second limitation of this study is that it only considered what taxonomists say, either in words or through citation. This means that the results do not reflect what taxonomists, and systematists more generally, actually do (Luckow 1995). Thus, it is possible that taxonomists claim to support the ESC and cite de Queiroz to support this, but use the same methods as 
taxonomists that a few decades ago claimed to rely on the BSC or PSC. A more exhaustive study should thus also look at taxonomic methods. This, of course, is tricky as there is no oneon-one link between species concepts and methods of species delimitation.

Finally, it is worth pointing out that the emerging consensus highlighted by the tests in this paper is more complex than might appear at first sight. Even among biologists that explicitly adopt de Queiroz's resolution of the species concepts, there are subtle disagreements about how this resolution should be interpreted. For example, both Padial and De La Riva (2020) and Zachos et al. (2019) explicitly endorse the ESC, but disagree on the question of whether there are subjective decisions in species delimitation. According to Zachos et al., grouping organisms into lineages is an objective matter while ranking lineages as species is a subjective matter. According to Padial and De La Riva, taxonomy does not require the subjective decision of ranking, as all and only phylogenetic lineages should be recognised as species. Despite the consensus on the ESC, then, there are still unresolved questions that continue to fuel debates between taxonomists. The tests in this paper are limited in that they gloss over these different interpretations of the paradigm, and only record explicit endorsement.

A third remark I wish to make is that, regardless of whether the unified species paradigm is conceptually sound or correct, its popularity should motivate philosophers of biology interested in species to (also) devote their attention to practical questions concerning species delimitation. While a substantial number of highly cited papers on species concepts were authored by philosophers, none of the highly cited papers on species delimitation were authored by philosophers. Indeed, a search for 'species delimitation' in PhilPapers yields almost no results. Recent philosophical work (Haber 2019; Sterner 2019) suggests that there are plenty of tricky conceptual issues in species delimitation that philosophers could explore and help clarifying. This paper has shown that in doing this, they would help developing a view that is increasingly important in systematic biology.

\section{Acknowledgments}

I am grateful to Andreas De Block, Lin Gen, and Lin Li for their comments on previous drafts of this paper. I also want to thank the two reviewers, Frank Zachos and John Wilkins, for their helpful suggestions. Research for this paper was funded by the Research Council-Flanders (FWO; Grant 3H200026).

\section{Literature cited}

Bornmann, Lutz, and Hans-Dieter Daniel. 2008. "What Do Citation Counts Measure? A Review of Studies on Citing Behavior." Journal of Documentation 64 (1): 45-80. https://doi.org/10.1108/ 00220410810844150.

Camargo, Arley, and Jack Sites. 2013. "Species Delimitation: A Decade after the Renaissance." In The Species Problem: Ongoing Issues, edited by Igor Pavlinov, 225-47. Rijeka: InTech.

Carstens, Bryan C., Tara A. Pelletier, Noah M. Reid, and Jordan D. Satler. 2013. "How to Fail at Species Delimitation.” Molecular Ecology 22 (17): 4369-83. https://doi.org/10.1111/mec.12413.

de Queiroz, Kevin. 1998. “The General Lineage Concept of Species, Species Criteria, and the Process of Speciation: A Conceptual Unification and Terminological Recommendations." In Endless Forms: Species and Speciation, edited by D Howard and S Berlocher, 57-75. Oxford, UK: Oxford University Press.

de Queiroz, Kevin. 2007. “Species Concepts and Species Delimitation.” Systematic Biology 56 (6): 879-86. https://doi.org/10.1080/10635150701701083. 
Ereshefsky, Marc. 2011. "Mystery of Mysteries: Darwin and the Species Problem." Cladistics 27 (1): 67-79. https://doi.org/10.1111/j.1096-0031.2010.00311.x.

Fišer, Cene, Christopher T. Robinson, and Florian Malard. 2018. "Cryptic Species as a Window into the Paradigm Shift of the Species Concept.” Molecular Ecology 27 (3): 613-35. https://doi.org/10. $1111 / \mathrm{mec} .14486$.

Fitzhugh, Kirk. 2009. "Species as Explanatory Hypotheses: Refinements and Implications." Acta Biotheoretica 57 (1): 201-48. https://doi.org/10.1007/s10441-009-9071-3.

Fontaine, Benoît, Kees van Achterberg, Miguel Angel Alonso-Zarazaga, Rafael Araujo, Manfred Asche, Horst Aspöck, Ulrike Aspöck, et al. 2012. "New Species in the Old World: Europe as a Frontier in Biodiversity Exploration, a Test Bed for 21st Century Taxonomy." Edited by Bernd Schierwater. PLoS ONE 7 (5): e36881. https://doi.org/10.1371/journal.pone.0036881.

Haber, Matthew H. 2019. "Species in the Age of Discordance." Philosophy, Theory, and Practice in Biology 11 (21). http://dx.doi.org/10.3998/ptpbio.16039257.0011.021.

Hunter, Malcolm L., and James P. Gibbs. 2009. Fundamentals of Conservation Biology. John Wiley \& Sons.

Krebs, Charles J. 2009. Ecology. Benjamin-Cummings Publishing Co.

Kuhn, Thomas S. 1962. The Structure of Scientific Revolutions. Chicago: University of Chicago Press.

Lakatos, Imre. 1976. "Falsification and the Methodology of Scientific Research Programmes." In Can Theories Be Refuted?, edited by Sandra D. Harding, 205-59. Synthese Library. Dordrecht: Springer. https://doi.org/10.1007/978-94-010-1863-0_14.

Leliaert, Frederik, and Olivier De Clerck. 2017. "Refining Species Boundaries in Algae." Journal of Phycology 53 (1): 12-16. https://doi.org/10.1111/jpy.12477.

Leliaert, Frederik, Heroen Verbruggen, Brian Wysor, and Olivier De Clerck. 2009. "DNA Taxonomy in Morphologically Plastic Taxa: Algorithmic Species Delimitation in the Boodlea Complex (Chlorophyta: Cladophorales)." Molecular Phylogenetics and Evolution 53 (1): 122-33. https://doi.org/10.1016/j.ympev.2009.06.004.

Luckow, Melissa. 1995. "Species Concepts: Assumptions, Methods, and Applications." Systematic Botany 20 (4): 589-605. https://doi.org/10.2307/2419812.

Lumbsch, H. Thorsten, and Steven D. Leavitt. 2011. "Goodbye Morphology? A Paradigm Shift in the Delimitation of Species in Lichenized Fungi." Fungal Diversity 50 (1): 59-72. https://doi. org/10.1007/s13225-011-0123-z.

Mallet, James. 2001. “Species Concepts.” In Encyclopedia of Biodiversity, edited by C. W. Fox and J. B. Wolf, 367-73. Oxford: Oxford University Press.

Mayden, R. 1997. "A Hierarchy of Species Concepts: The Denouement in the Saga of the Species Problem." In Species, the Units of Biodiversity, Systematics Association Special Volume Series, edited by M. Claridge, H. Dawah, and Robert A. Wilson, 381-424. London: Chapman \& Hall.

Mishler, Brent D. 2009. "Three Centuries of Paradigm Changes in Biological Classification: Is the End in Sight?" Taxon 58 (1): 61-67.

Padial, José M., and Ignacio De La Riva. 2020. "A Paradigm Shift in Our View of Species Drives Current Trends in Biological Classification.” Biological Reviews 96 (2): 731-751. https://doi.org/ 10.1111/brv.12676

Padial, José M., and Ignacio De La Riva. 2010. "A Response to Recent Proposals for Integrative Taxonomy." Biological Journal of the Linnean Society 101 (3): 747-56. https://doi.org/10.1111/j. 1095-8312.2010.01528.x. 
Padial, José M., Aurélien Miralles, Ignacio De la Riva, and Miguel Vences. 2010. “The Integrative Future of Taxonomy." Frontiers in Zoology 7 (16): 1-14. https://doi.org/10.1186/1742-9994-7-16.

Petrovich, Eugenio. 2018. "Accumulation of Knowledge in Para-Scientific Areas: The Case of Analytic Philosophy.” Scientometrics 116 (2): 1123-51. https://doi.org/10.1007/s11192-018-2796-5.

Pušić, Bruno, Pavel Gregorić, and Damjan Franjević. 2017. "What Do Biologists Make of the Species Problem?” Acta Biotheoretica 65 (3): 179-209. https://doi.org/10.1007/s10441-017-9311-x.

Schlick-Steiner, Birgit C., Florian M. Steiner, Bernhard Seifert, Christian Stauffer, Erhard Christian, and Ross H. Crozier. 2010. "Integrative Taxonomy: A Multisource Approach to Exploring Biodiversity." Annual Review of Entomology 55 (1): 421-38. https://doi.org/10.1146/ annurev-ento-112408-085432.

Simpson, George Gaylord. 1951. “The Species Concept.” Evolution 5 (4): 285-98. https://doi.org/10. 2307/2405675.

Sites, Jack W., and Jonathon C. Marshall. 2003. "Delimiting Species: A Renaissance Issue in Systematic Biology." Trends in Ecology \& Evolution 18 (9): 462-70. https://doi.org/10.1016/ S0169-5347(03)00184-8.

Small, Henry. 1982. “Citation Context Analysis.” Progress in Communication Sciences 3:287-310.

Smith, Thomas M., and Robert Leo Smith. 2015. Elements of Ecology. Pearson.

Sterner, Beckett W. 2019. "Evolutionary Species in Light of Population Genomics." Philosophy of Science 86 (5): 1087-89. https://doi.org/10.1086/705527.

Sukumaran, Jeet, and L. Lacey Knowles. 2017. "Multispecies Coalescent Delimits Structure, Not Species." Proceedings of the National Academy of Sciences 114 (7): 1607-12. https://doi.org/10.1073/ pnas.1607921114.

Townsend, Colin R., Michael Begon, and John L. Harper. 2008. Essentials of Ecology. Wiley.

Weisrock, David W., Rodin M. Rasoloarison, Isabella Fiorentino, José M. Ralison, Steven M. Goodman, Peter M. Kappeler, and Anne D. Yoder. 2010. "Delimiting Species without Nuclear Monophyly in Madagascar's Mouse Lemurs.” PLoS ONE 5 (3). https://doi.org/10.1371/journal.pone. 0009883 .

Wiley, E. O. 1978. “The Evolutionary Species Concept Reconsidered.” Systematic Biology 27 (1): 1726. https://doi.org/10.2307/2412809.

Wilkins, John S. 2018. Species: The Evolution of the Idea. Boca Raton, FL: CRC Press.

Zachos, Frank E. 2016. Species Concepts in Biology: Historical Development, Theoretical Foundations and Practical Relevance. Basel: Springer.

Zachos, Frank E. 2018. “(New) Species Concepts, Species Delimitation and the Inherent Limitations of Taxonomy." Journal of Genetics 97 (4): 811-15. https://doi.org/10.1007/s12041-018-0965-1.

Zachos, Frank E., Les Christidis, and Stephen T. Garnett. 2019. "Mammalian Species and the Twofold Nature of Taxonomy: A Comment on Taylor et al. 2019.” Mammalia 84 (1): 1-5. https://doi.org/10.1515/mammalia-2019-0009.

(C) 2022 Author(s)

This is an open-access article distributed under the terms of the Creative Commons Attribution 4.0 International license, which permits anyone to download, copy, distribute, display, or adapt the text without asking for permission, provided that the creator(s) are given full credit. 


\section{Appendix: Supplementary Materials}

\section{A Search terms}

Species delimitation: I performed a search in Clarivate's Web of Science, Core Collection for all document types in English on April 1, 2020 for the following: TI="species delimitation".

Species concept: I performed a search in Clarivate's Web of Science, Core Collection for all document types in English on April 1, 2020 for the following: TI="species concept" OR "species definition" OR "concept of species" OR "definition of species".

Various species concepts: I performed a search in Clarivate's Web of Science, Core Collection for all document types in English on April 1, 2020 for the following: TS= "biological species concept" OR "phylogenetic species concept" OR "ecological species concept" OR "recognition species concept" OR "cohesion species concept" OR "genotypic cluster species concept" OR "genealogical concordance species concept" OR "genetic species concept" OR "taxonomic species concept”.

\section{B Textbooks consulted}

Table A1: Textbooks about biology in general. For each textbook, I consulted the chapters indicated in the final column, and searched in the index for 'species', 'taxonomy' and 'classification'.

Table A2: Textbooks about evolutionary biology. For each textbook, I consulted the chapters indicated in the final column, and searched in the index for 'species', 'taxonomy' and 'classification'.

\section{List of all species concepts}

Table A3 lists all papers used for the test of prediction 1 in section 3.

\section{$D \quad$ List of selected species concepts}

Table A4 lists the selection of non-ESC species concepts used for the citation context analysis, and the reference used for each of these concepts.

\section{E List of relevant Web of Science Research Areas}

Table A5 lists the top 15 research areas in Web of Science that cite the references listed in table A4 most often. 
Table A1: All general biology textbooks included in the textbook survey.

\begin{tabular}{|c|c|c|c|c|c|c|}
\hline Name & Title & Authors & Ed. & Date & Publisher & Chapters \\
\hline \multirow[t]{10}{*}{ Campbell } & Biology & Neil Campbell & 2 & 1990 & $\begin{array}{l}\text { Ben- } \\
\text { jamin/Cummings } \\
\text { Publishing Co. }\end{array}$ & 22,23 \\
\hline & Biology & Neil Campbell & 3 & 1993 & $\begin{array}{l}\text { Ben- } \\
\text { jamin/Cummings } \\
\text { Publishing Co. }\end{array}$ & 22,23 \\
\hline & Biology & Neil Campbell & 4 & 1996 & $\begin{array}{l}\text { Ben- } \\
\text { jamin/Cummings }\end{array}$ & 22,23 \\
\hline & Biology & $\begin{array}{l}\text { Neil Campbell, Jane Reece, Lawrence } \\
\text { Mitchell }\end{array}$ & 5 & 1999 & $\begin{array}{l}\text { Publishing Co. } \\
\text { Addison Wesley } \\
\text { Longman }\end{array}$ & 24,25 \\
\hline & Biology & Neil Campbell, Jane Reece & 6 & 2002 & $\begin{array}{l}\text { Addison Wesley } \\
\text { Longman }\end{array}$ & 24,25 \\
\hline & Biology & Neil Campbell, Jane Reece & 7 & 2005 & $\begin{array}{l}\text { Pearson } \\
\text { Benjamin } \\
\text { Cummings }\end{array}$ & 24,25 \\
\hline & Biology & $\begin{array}{l}\text { N. Campbell, J. Reece, L. Urry, M. } \\
\text { Cain, S. Wasserman, P. Minorsky, R. } \\
\text { Jackson }\end{array}$ & 8 & 2008 & $\begin{array}{l}\text { Pearson } \\
\text { Benjamin } \\
\text { Cummings }\end{array}$ & 24,26 \\
\hline & Biology & $\begin{array}{l}\text { N. Campbell, J. Reece, L. Urry, M. } \\
\text { Cain, S. Wasserman, P. Minorsky, R. } \\
\text { Jackson }\end{array}$ & 9 & 2011 & $\begin{array}{l}\text { Benjamin } \\
\text { Cummings }\end{array}$ & 24,26 \\
\hline & Biology & $\begin{array}{l}\text { N. Campbell, J. Reece, L. Urry, M. } \\
\text { Cain, S. Wasserman, P. Minorsky, R. } \\
\text { Jackson }\end{array}$ & 10 & 2013 & Pearson & 24,26 \\
\hline & Biology & $\begin{array}{l}\text { Lisa Urry, Michael Cain, Steven } \\
\text { Wasserman, Peter Minorsky, Robert } \\
\text { Jackson }\end{array}$ & 11 & 2017 & Pearson & 24,26 \\
\hline \multirow[t]{9}{*}{ Solomon } & Biology & $\begin{array}{l}\text { Claude Villee, Eldra Solomon, } \\
\text { William Davis }\end{array}$ & 1 & 1985 & $\begin{array}{l}\text { Saunders College } \\
\text { Publishing }\end{array}$ & 17,45 \\
\hline & Biology & $\begin{array}{l}\text { Eldra Solomon, Linda Berg, Diana } \\
\text { Martin, Claude Villee }\end{array}$ & 3 & 1993 & $\begin{array}{l}\text { Saunders College } \\
\text { Publishing }\end{array}$ & 19,22 \\
\hline & Biology & $\begin{array}{l}\text { Eldra Solomon, Linda Berg, Diana } \\
\text { Martin, Claude Villee }\end{array}$ & 4 & 1996 & $\begin{array}{l}\text { Saunders College } \\
\text { Publishing }\end{array}$ & 19,22 \\
\hline & Biology & $\begin{array}{l}\text { Eldra Solomon, Linda Berg, Diana } \\
\text { Martin }\end{array}$ & 5 & 1999 & $\begin{array}{l}\text { Saunders College } \\
\text { Publishing }\end{array}$ & 19,22 \\
\hline & Biology & $\begin{array}{l}\text { Eldra Solomon, Linda Berg, Diana } \\
\text { Martin }\end{array}$ & 7 & 2005 & Brooks/Cole & 19,22 \\
\hline & Biology & $\begin{array}{l}\text { Eldra Solomon, Linda Berg, Diana } \\
\text { Martin }\end{array}$ & 8 & 2008 & Brooks/Cole & 20,23 \\
\hline & Biology & $\begin{array}{l}\text { Eldra Solomon, Linda Berg, Diana } \\
\text { Martin }\end{array}$ & 9 & 2011 & Brooks/Cole & 20,23 \\
\hline & Biology & $\begin{array}{l}\text { Eldra Solomon, Charles Martin, } \\
\text { Diana Martin, Linda Berg }\end{array}$ & 10 & 2015 & $\begin{array}{l}\text { Cengage } \\
\text { Learning }\end{array}$ & 20,23 \\
\hline & Biology & $\begin{array}{l}\text { Eldra Solomon, Charles Martin, } \\
\text { Diana Martin, Linda Berg }\end{array}$ & 11 & 2019 & $\begin{array}{l}\text { Cengage } \\
\text { Learning }\end{array}$ & 20,23 \\
\hline
\end{tabular}


Table A1: continued

\begin{tabular}{|c|c|c|c|c|c|c|}
\hline Name & Title & Authors & Ed. & Date & Publisher & Chapters \\
\hline \multirow[t]{6}{*}{ Raven } & Biology & Peter Raven, George Johnson & 5 & 1999 & McGraw-Hill & 21,28 \\
\hline & Biology & Peter Raven, George Johnson & 6 & 2002 & McGraw-Hill & 22,32 \\
\hline & Biology & $\begin{array}{l}\text { Peter Raven, George Johnson, } \\
\text { Jonathan Losos, Susan Singer }\end{array}$ & 7 & 2005 & McGraw-Hill & 23,25 \\
\hline & Biology & $\begin{array}{l}\text { Jonathan Losos, Kenneth Mason, } \\
\text { Susan Singer }\end{array}$ & 8 & 2008 & McGraw-Hill & 22,23 \\
\hline & Biology & $\begin{array}{l}\text { Kenneth Mason, Jonathan Losos, } \\
\text { Susan Singer }\end{array}$ & 9 & 2011 & McGraw-Hill & 22,23 \\
\hline & Biology & $\begin{array}{l}\text { Kenneth Mason, Jonathan Losos, } \\
\text { Susan Singer }\end{array}$ & 11 & 2017 & McGraw-Hill & 22,23 \\
\hline \multirow[t]{3}{*}{ Kimball } & Biology & John Kimball & 3 & 1975 & $\begin{array}{l}\text { Addison Wesley } \\
\text { Publishing Co. }\end{array}$ & 32 \\
\hline & Biology & John Kimball & 4 & 1978 & $\begin{array}{l}\text { Addison Wesley } \\
\text { Publishing Co. }\end{array}$ & 32,33 \\
\hline & Biology & John Kimball & 5 & 1982 & $\begin{array}{l}\text { Addison Wesley } \\
\text { Publishing Co. }\end{array}$ & 33,35 \\
\hline
\end{tabular}

Table A2: All textbooks on evolutionary biology included in the survey.

\begin{tabular}{|c|c|c|c|c|c|c|}
\hline Name & Title & Authors & $\begin{array}{l}\text { Edi- } \\
\text { tion }\end{array}$ & $\begin{array}{l}\text { Publica- } \\
\text { tion year }\end{array}$ & Publisher & $\begin{array}{l}\text { Chapters } \\
\text { consulted }\end{array}$ \\
\hline \multirow[t]{5}{*}{ Futuyma } & $\begin{array}{l}\text { Evolutionary } \\
\text { Biology }\end{array}$ & Douglas Futuyma & 2 & 1986 & \multirow{5}{*}{$\begin{array}{l}\text { Sinauer } \\
\text { Associates Inc. } \\
\text { Sinauer } \\
\text { Associates Inc. } \\
\text { Sinauer } \\
\text { Associates Inc. } \\
\text { Sinauer } \\
\text { Associates Inc. } \\
\text { Sinauer } \\
\text { Associates Inc. }\end{array}$} & 8,10 \\
\hline & $\begin{array}{l}\text { Evolutionary } \\
\text { biology }\end{array}$ & Douglas Futuyma & 3 & 1998 & & 2,17 \\
\hline & Evolution & Douglas Futuyma & 1 & 2005 & & 2,15 \\
\hline & Evolution & Douglas Futuyma & 3 & 2013 & & 5,15 \\
\hline & Evolution & $\begin{array}{l}\text { Douglas Futuyma, } \\
\text { Mark Kirkpatrick }\end{array}$ & 4 & 2017 & & 2,9 \\
\hline \multirow[t]{2}{*}{ Freeman } & $\begin{array}{l}\text { Evolutionary } \\
\text { analysis }\end{array}$ & $\begin{array}{l}\text { Scott Freeman, John } \\
\text { Herron }\end{array}$ & 2 & 2001 & Prentice Hall & 12,13 \\
\hline & $\begin{array}{l}\text { Evolutionary } \\
\text { analysis }\end{array}$ & $\begin{array}{l}\text { John Herron, Scott } \\
\text { Freeman }\end{array}$ & 5 & 2014 & Pearson & 4,16 \\
\hline \multirow[t]{2}{*}{ Ridley } & Evolution & Mark Ridley & 3 & 2004 & Blackwell & 13,16 \\
\hline & Evolution & Mark Ridley & 1 & 1993 & Blackwell & 14,15 \\
\hline
\end{tabular}


Table A3: The non-ESC species concepts selected for the citation context analysis, each with the reference used to retrieve citing documents from WoS, and how often these documents were cited in Google Scholar on $1 / 4 / 2020$ (used as a selection criterion).

\begin{tabular}{llr}
\hline Species Concept & Reference & Google Scholar Citations \\
\hline Phylogenetic Species Concept (monophyly) & Donoghue (1985) & 612 \\
Phylogenetic Species Concept (Diagnosability) & Cracraft (1983) & 1748 \\
Biological Species Concept & Mayr (1942) & 8551 \\
Ecological Species Concept & Valen (1976) & 927 \\
Recognition Species Concept & Paterson (1985) & 1252 \\
Cohesion Species Concept & Templeton (1989) & 1078 \\
Genotypic Cluster Concept & Mallet (1995) & 939 \\
\hline
\end{tabular}


Table A4: List of all species concepts with their main references, the group they were included in for prediction 1 , and reasons for exclusion of excluded concepts.

\begin{tabular}{|c|c|c|}
\hline Species Concept & $\begin{array}{l}\text { Selected } \\
\text { References }\end{array}$ & Group Prediction 1 \\
\hline Agamospecies Concept & Cain (1954) & Excluded (no citations) \\
\hline Biological Species Concept & $\begin{array}{l}\text { Mayr (2000, } \\
1996,1940)\end{array}$ & Other concepts \\
\hline Biosimilarity Species Concept & Stamos (2003) & Other concepts \\
\hline Cladistic Species Concept & Ridley (1989) & Other concepts \\
\hline Cohesion Species Concept & $\begin{array}{l}\text { Templeton } \\
\text { (1989) }\end{array}$ & Other concepts \\
\hline Compilospecies Concept & $\begin{array}{l}\text { Harlan \& De } \\
\text { Wet (1963) }\end{array}$ & Other concepts \\
\hline Differential Fitness Species Concept & $\begin{array}{l}\text { Hausdorf } \\
\text { (2011) }\end{array}$ & Other concepts \\
\hline Ecological Species Concept & Valen (1976) & Other concepts \\
\hline Evolutionary Significant Unit & Moritz (1994) & Excluded (not a species concept) \\
\hline Evolutionary Species Concept & $\begin{array}{l}\text { Wiley (1978), } \\
\text { Simpson } \\
\text { (1951) }\end{array}$ & ESC \\
\hline Genealogical Concordance Species Concept & $\begin{array}{l}\text { Avise \& Ball } \\
\text { (1990) }\end{array}$ & Other concepts \\
\hline Genealogical Species Concept & $\begin{array}{l}\text { Baum \& Shaw } \\
\text { (1995) }\end{array}$ & Other concepts \\
\hline General Lineage Species Concept & $\begin{array}{l}\text { de Queiroz } \\
(1998,2007)\end{array}$ & ESC \\
\hline Genetic Species Concept & $\begin{array}{l}\text { Baker \& } \\
\text { Bradley (2006) }\end{array}$ & Other concepts \\
\hline Genic Species Concept & $\mathrm{Wu}(2001)$ & Other concepts \\
\hline Genotypic Cluster Species Concept & Mallet (1995) & Other concepts \\
\hline Hennigian Species Concept & $\begin{array}{l}\text { Meier \& } \\
\text { Willmann } \\
(2000)\end{array}$ & Other concepts \\
\hline Inclusive Species Concept & $\begin{array}{l}\text { Shanker et al. } \\
\text { (2017) }\end{array}$ & Other concepts \\
\hline Internodal Species Concept & Kornet (1993) & Other concepts \\
\hline Least Inclusive Taxonomic Unit & Pleijel (1999) & Excluded (not a species concept) \\
\hline Mitonuclear Compatibility Species Concept & Hill (2017) & Other concepts \\
\hline Morphological Species Concept & $\begin{array}{l}\text { Cronquist } \\
\text { (1978) }\end{array}$ & Excluded (not indexed) \\
\hline Non-dimensional Species Concept & $\begin{array}{l}\text { Mayr (2000, } \\
1996,1940)\end{array}$ & Excluded (not a species concept) \\
\hline Nothospecies Concept & Wagner (1983) & Excluded (not indexed) \\
\hline Phenetic Species Concept & $\begin{array}{l}\text { Sokal \& Sneath } \\
\text { (1963) }\end{array}$ & Excluded (no citations) \\
\hline Phylogenetic Species Concept (Diagnosability Version) & $\begin{array}{l}\text { Cracraft (1983), } \\
\text { Nixon \& } \\
\text { Wheeler } \\
\text { (1990), } \\
\text { Wheeler \& } \\
\text { Platnick (2000) }\end{array}$ & Other concepts \\
\hline
\end{tabular}


Table A4: continued

\begin{tabular}{lll}
\hline Species Concept & Selected References & Group Prediction 1 \\
\hline Phylogenetic Species Concept (monophyly version) & $\begin{array}{l}\text { Mishler \& Brandon } \\
(1987), \text { Donoghue }\end{array}$ & Other concepts \\
& $\begin{array}{l}\text { (1985), Mishler (1985), } \\
\text { Mishler \& Donoghue }\end{array}$ & \\
& $(1982)$ & \\
& Rossello-Mora R \& & Other concepts \\
Phylo-Phenetic Species Concept & Amann R (2001) & \\
& Seifert (2014) & Other concepts \\
Pragmatic Species Concept & Paterson (1985) & Other concepts \\
Recognition Species Concept & Ghiselin (1974) & Excluded (identical to BSC) \\
Reproductive Competition Species Concept & Simpson (1961) & Excluded (no citations) \\
Successional Species Concept & Blackwelder (1967) & Excluded (no citations) \\
Taxonomic Species Concept & de Queiroz (1998, & ESC \\
Unified Species Concept & $2007)$ & \\
& & \\
\hline
\end{tabular}

Table A5: Top 15 research areas in Web of Science citing papers about species concepts.

\begin{tabular}{lrr}
\hline Research Areas & Total citations of species concept papers & Proportion of total \\
\hline Evolutionary biology & 6540 & $71 \%$ \\
Genetics heredity & 6379 & $70 \%$ \\
Life sciences biomedicine other topics & 5852 & $64 \%$ \\
Zoology & 5654 & $62 \%$ \\
Environmental sciences ecology & 4156 & $45 \%$ \\
Biochemistry molecular biology & 3791 & $41 \%$ \\
Biodiversity conservation & 2237 & $24 \%$ \\
Plant sciences & 2049 & $22 \%$ \\
Anatomy morphology & 1741 & $19 \%$ \\
Microbiology & 1308 & $14 \%$ \\
Science technology other topics & 1185 & $13 \%$ \\
Reproductive biology & 977 & $10 \%$ \\
Marine freshwater biology & 862 & $9 \%$ \\
Immunology & 857 & $9 \%$ \\
\hline
\end{tabular}

